\title{
Foreign Language Anxiety: Classroom VS Distance Learning
}

\author{
Lisnychenko Alla*, Dovhaliuk Tamila, Khamska Neonila, Glazunova Tamara \\ Department of Foreign Languages, Vinnytsia Mykhailo Kotsiubynskyi State Pedagogical University, Vinnytsia, 21021, Ukraine
}

Received August 30, 2020; Revised October 27, 2020; Accepted November 11, 2020

\section{Cite This Paper in the following Citation Styles}

(a): [1] Lisnychenko Alla, Dovhaliuk Tamila, Khamska Neonila, Glazunova Tamara, "Foreign Language Anxiety: Classroom VS Distance Learning," Universal Journal of Educational Research, Vol. 8, No. 12, pp. 6684 - 6691, 2020. DOI: 10.13189/ujer.2020.081233.

(b): Lisnychenko Alla, Dovhaliuk Tamila, Khamska Neonila, Glazunova Tamara (2020). Foreign Language Anxiety: Classroom VS Distance Learning. Universal Journal of Educational Research, 8(12), 6684 - 6691. DOI: 10.13189/ujer.2020.081233.

Copyright $C 2020$ by authors, all rights reserved. Authors agree that this article remains permanently open access under the terms of the Creative Commons Attribution License 4.0 International License

\begin{abstract}
Anxiety is a powerful affective factor that makes a negative impact on the foreign language learning and performance. It is important to be aware of the learning conditions that can influence the foreign language anxiety level. The primary aim of this study was to examine the difference in students' foreign language anxiety level in classroom and distance learning environments. The given investigation was conducted in the Vinnytsia Mykhailo Kotsiubynskyi State Pedagogical University, Ukraine, in the spring semester, 2020, and involved 38 students of the 1-st and 2-nd years of studying. The comparative analysis of the students' foreign language anxiety levels in traditional classroom and distance learning environments has been carried out. A survey method engaging the use of FLCAS with 5 -point-items Likert scale was employed. The obtained results have demonstrated a significant increase in communication apprehension and fear of negative evaluation anxiety types as well as a slight decrease in test anxiety and fear of making mistakes. The factors that caused such changes have been analyzed and defined. Among the main negative-bearing factors are the changes in the learning context and the character of distance online learning per se. The reasons for positive changes in the students' foreign language anxiety levels are - flexibility of the schedule, growing autonomy of the students and improved test-taking skills. Possible ways of reducing foreign language anxiety, such as developing students' awareness of foreign language anxiety and its symptoms, computer-based communication competency, peer support and learner autonomy have been suggested. The major
\end{abstract}

conclusion made is that anxiety is a labile foreign language learning factor, which can be changed in the new learning context. Hence, the task of foreign language teachers is to reduce foreign language anxiety by taking into account the aforementioned factors.

Keywords Foreign Language Anxiety, Classroom Learning, Distance Learning, Communication Apprehension, Test Anxiety, Fear of Negative Evaluation

\section{Introduction}

Anxiety has always been going alongside the process of teaching foreign languages in Ukraine. To understand its nature and source, one has to take a closer look at the learning context in this country, which is deeply rooted in the teaching traditions of the 19th century. GrammarTranslation method predominating in the first part of the last century was combined with some elements of Audiolingual and Communicative approaches later, in the second part of the century. Teacher-centered foreign language teaching process was heavily focused on form and grammatical accuracy of speech, which was a source of fear of making mistakes. Communication as such boiled down to teacher-student question-answer format, almost devoid of spontaneity, which made unprepared speaking another source of anxiety. Being a part of the USSR and living behind the "iron gate" until 1991, the Ukrainians had very little opportunity to communicate with native 
speakers of the English language. Needless to say, when such an opportunity did arise, they felt anxious and panicky. The 21st century sets new perspectives and goals before Ukrainian teachers of English. With learner-centeredness and communicative competence being the priority of modern foreign language teaching, switching to a different mode of teaching and learning is not an easy matter for both -teachers and students of Ukraine and they still face fears and anxiety connected with foreign language learning.

The COVID-19 pandemic in Ukraine had a considerable impact on the learning situation. When the nation-wide lockdown was established in Ukraine on March 11, 2020, all educational establishments switched to distance learning. We believe that this change of the broader context, in general, and the learning situation, in particular, has influenced psychological condition of Ukrainian students.

This study is aimed to examine the difference in students' foreign language anxiety rates in classroom and distance learning environments.

The research questions considered in the present study are the following:

1. What impact does the transition from classroom to distance mode of learning have on foreign language anxiety?

2. What are the possible ways of reducing foreign language anxiety in the distance online learning context?

\section{Theoretical Background}

\subsection{The Concept of Foreign Language Learning Anxiety}

Anxiety in any of its manifestations has a detrimental effect on the process of foreign language learning. Probably, no other field of research requires self-expression as much as a language does. Exactly this factor distinguishes anxiety in foreign language learning from other types of "learning" anxiety.

Since foreign language learning anxiety is mainly caused by the assessment of oral and written speech in academic and social contexts, it is appropriate to consider the following three types of anxiety, namely: 1) communication apprehension; 2) test anxiety, caused by the control of knowledge and skills; and 3) fear of negative evaluation by other students and the teacher.

Communication anxiety is shyness caused by the need to communicate in English with other students and teachers. The peculiar manifestations of this type of anxiety are difficulties that arise while working in pairs or groups (anxiety associated with oral communication), or while listening (anxiety associated with the perception of oral speech by ear). It is clear that communication anxiety is leading among other types of foreign language learning. Communication apprehension can also be easily recognized by the following symptoms: clenching or wringing one's hands, pacing back and forth, keeping hands in pockets, feeling panicky and very self-conscious when having to speak without preparation in language class in front of other students.

Assessment of students' speech is an integral feature of most foreign language lessons. So, the anxiety caused by the control of foreign language skills should also be taken into consideration. At the heart of this type of anxiety is the fear of failure. Students who have this type of anxiety set unrealistic goals and consider any result to be a failure if it is lower than ideal. As tests and quizzes are performed quite often in foreign language classes and even the most prepared students make mistakes, the anxiety associated with control may cause real sufferings [1].

The most typical symptoms of test anxiety admitted by students themselves are the following:

- test apprehension when students get overwhelmed and confused by the amount of material they have to cover

- nervousness during a language class that causes students to forget the things they have learnt

- fear of failure at a language class or an examination

- feeling of being overwhelmed by the number of grammar rules to be learned to master a foreign language.

The third type of anxiety associated with foreign language learning is the fear of negative evaluation, which is defined as "student's fear of assessment by others, avoidance of situations in which assessment is given, confidence that others will evaluate them negatively." The fear of negative evaluation is broader than the anxiety caused by the teacher's control of foreign language skills, as it is not limited to testing situations - this type of anxiety can be caused by any social or academic situation related to assessment, such as a job interview, for example, or having to speak in a foreign language class [2].

The most common symptoms of this type of anxiety experienced and mentioned by students are:

- concern about making mistakes in a language class

- fear of being constantly corrected and laughed at

- feeling that fellow students are better at English than they are

- fear of being left behind

- feeling of embarrassment that prevents students from volunteering answers

- physical symptoms (pounding heart, sweating palms, shaking hands etc.)" [3].

\subsection{Literature Review}

Literature analysis shows that anxiety in classroom-based foreign language learning has been the object of a lot of research $[3,4,5,6,7]$. The findings of studies on classroom foreign language anxiety are constantly updating due to researchers' interest to anxiety as an influential affective variable in foreign language 
learning and presence of issues which prompt further investigation. Recent research in this field supports a number of studies, which demonstrated negative correlation between anxiety and students' academic performance [8,9], gives extended summary of the information and research findings on foreign language anxiety causes and consequences [10,11], provides characteristics of various anxiety reducing strategies $[12,13]$.

However, we have found out that, researchers mostly concentrate on anxiety in conventional face-to-face foreign language classes and little attention is given to the exploration of this complex psychological phenomenon in foreign language learning at a distance, though the anxiety role in a distance language learning environment might be considerable. The evidence for that is Hurd's [14] research results. She found that the distance language anxiety in language learning is linked to specific provoking factors: the contradiction between social character of language learning and a distance mode of this activity, lack of instant feedback, lack of opportunities for speaking practice, lack of confidence when working on one's own. Nielson and Gonzalez-Lloret [15] point out other reasons that lead to anxiety: lack of community and "time lag in interaction". The researchers emphasize, that these factors are especially important for foreign language instruction as learning there occurs through interaction and acquisition is dependent upon feedback and noticing. Delay in interaction, according to Nielson and Gonzalez-Lloret, can influence negatively learners' ability to pay attention to interactions and incorporate feedback.

These described above research findings support the media naturalness theory (psychobiological model), developed by Kock [16], according to which, distance language learning being not a natural way to communicate leads to an increase in students' cognitive effort, an increase in communication ambiguity and a decrease in physical arousal (or excitement) and, thus, influences negatively students' affective domain.

Only learners with a high level of motivation and self-management skills can experience no or little causal effect of distance education $[17,18,19]$.

Besides, Russell [20] suggests that distance learners' anxiety might have been intensified in our present situation due to COVID-19, when students have been engaged into online language learning with the lack of agency in the selection of their instructional delivery mode on their part.

All anxiety-provoking factors taken into consideration seem to be a weighty argument to hypothesize high level anxiety among distance language learners. However, the review of the literature indicates that the research into foreign language learner anxiety in an online setting manifests contradicting results. For example, Jegede and Kirkwood [21] examined the level of anxiety of 222 distance students in University of Southern Queensland using the Docking's affect adjective checklist, modified for distance learners, and a students' opinionnaire on factors, which affect learning at a distance. Their research showed that the students had a very high level of anxiety and were on the whole more anxious about their studies at the end of the semester than at the beginning. Similarly, the study of Ajmal [22] revealed a significant effect of anxiety on the academic performance of distance learners in Allama Iqbal Open University. For the study instrument the researchers used the questionnaire based on five-point Likert scale.

On the contrary, other researchers reported about mainly positive relationship between reduced learning anxiety and the use of multimedia environment [23] and e-learning [24]. These findings were generally supported by the study on online language learning anxiety among adult learners [25].

The research, comparing the influence of anxiety on language learning in conventional and non-conventional settings, received only scant attention.

Pichette [26] compared in his study anxiety profiles of traditional and distance language learners at different levels. The researcher used Foreign Language Classroom Anxiety Scale (Horwitz, 1986), the Foreign Language Reading Anxiety Scale (Saito, Garza and Horwitz, 1999), and the Daly-Miller Writing Apprehension Test (Daly and Miller, 1975). The results of his research revealed no differences in anxiety profiles between classroom and distance learners when all levels of learners were combined, and lower level of anxiety among advanced online students comparing to the level of anxiety among first-semester students in traditional classes.

A longitudinal study was conducted by Hurd [14] to explore the nature of language anxiety in a distance learning environment and the strategies students should use to cope with it. In the research questionnaires, think-aloud protocols and one-to-one telephone interviews were used with distance students learning French at The Open University (UK). The findings indicated that $21 \%$ of the students after four months of study felt that learning at a distance made them more anxious than learning in a classroom, $27 \%$ found that the distance factor made them less anxious and $51.7 \%$ of the students did not consider that the learning setting influenced their education achievements.

In another distance and online learning context Bollinger [27] compared foreign language students' achievement and foreign language anxiety scores based on their foreign language anxiety levels and their learning environment, using the Foreign Language Classroom Anxiety Scale. The findings of the study indicated that the students in traditional foreign language classes were less anxious than in distance learning foreign language classes.

\section{Research Methodology}

\subsection{Participants}

The given investigation was conducted on the basis of 
the Vinnytsia Mykhailo Kotsiubynskyi State Pedagogical University (VSPU) in Spring Semester, 2020, and involved 38 students of the 1-st and 2-nd years of studying their B. Ed programme. The peculiarity of this research lies in the fact that the same group of participants was engaged both in classroom (February - March 11) and distance foreign language (March 11 - May 31) learning to meet the quarantine requirements in the face of corona virus threats. The distance learning was conducted online through Zoom and Google-classroom excluding face-to-face contact sessions.

\subsection{Materials and Methods}

The empirical data was collected by survey with the use of Foreign Language Classroom Anxiety Scale (FLCAS) [3]. The choice of FLCAS as the main instrument of investigation can be explained by its reliability and validity when applied for both classroom setting [28] and online teaching $[26,20]$. In the 5-point-items Likert scale point 1 is "Strongly Agree", point 5 is "Strongly Disagree" in statements $2,5,8,11,14,18,22,28,32$. In the rest of the statements point 1 corresponds to "Strongly Disagree", point 5 - to "Strongly Agree", accordingly. The FLCAS questionnaire, administered in February, aimed at the evaluation of the type and severity of the English Language learning in a traditional classroom setting. The same kind of survey was performed on the same group of students in June, 2020, after a 3-months period of distance learning, required by the quarantine regulations. Its purpose was to evaluate the types and levels of anxiety, connected with distance learning. The comparative analysis of the results of both surveys, performed by means of the t-Student test, reflected the changes in the character and degree of foreign language anxiety under the influence of changing the modes of teaching by switching from face-to-face classroom learning to distance, online learning (Table 1).

Table 1. Comparison of the Foreign Language Anxiety Scores after Classroom and Distance Learning

\begin{tabular}{|c|c|c|c|}
\hline No & Classroom learning & Distance Learning & t-test \\
\hline & Mean Score & Mean Score & absolute value \\
\hline \multirow[t]{2}{*}{1} & \multicolumn{3}{|c|}{ I never feel quite sure of myself when I am speaking in my English class } \\
\hline & 2.5 & 2.6 & 0.47 \\
\hline \multirow[t]{2}{*}{2} & \multicolumn{3}{|c|}{ I don't worry about making mistakes in my English Class } \\
\hline & 3.38 & 2.83 & -2.29 \\
\hline 3 & \multicolumn{3}{|c|}{ I tremble when I know that I'm going to be called on in my English class } \\
\hline & 3.16 & 2.94 & -0.82 \\
\hline 4 & \multicolumn{3}{|c|}{ It frightens me when I don't understand what the teacher is saying in the English class } \\
\hline & 3 & 3.1 & 0.5 \\
\hline 5 & \multicolumn{3}{|c|}{ It wouldn't bother me at all to take more English language classes } \\
\hline & 2.5 & 1.94 & -2.49 \\
\hline 6 & \multicolumn{3}{|c|}{ During English class I find myself thinking about things that have nothing to do with the course } \\
\hline & 3.78 & 3.52 & -0.9 \\
\hline 7 & \multicolumn{3}{|c|}{ I keep thinking that the other students are better at English than I am } \\
\hline & 2.28 & 2.86 & 2.29 \\
\hline 8 & \multicolumn{3}{|c|}{ I am usually at ease during my English class } \\
\hline & 2.47 & 2.42 & -0.27 \\
\hline 9 & \multicolumn{3}{|c|}{ I start to panic when I have to speak without preparation in my English class } \\
\hline & 2.78 & 2.97 & 0.72 \\
\hline 10 & \multicolumn{3}{|c|}{ I worry about the consequences of failing my English class } \\
\hline & 2.67 & 2.75 & 0.3 \\
\hline 11 & \multicolumn{3}{|c|}{ I don't understand why some people get so upset over English class } \\
\hline & 2.97 & 2.78 & -0.81 \\
\hline 12 & \multicolumn{3}{|c|}{ In English class, I can get so nervous I forget things I know } \\
\hline & 2.58 & 2.47 & -0.49 \\
\hline
\end{tabular}


Table 1 Continuous

\begin{tabular}{|c|c|c|c|}
\hline \multirow[t]{2}{*}{13} & \multicolumn{3}{|c|}{ It embarrasses me to volunteer answers in my English class } \\
\hline & 2.44 & 2.58 & 0.53 \\
\hline \multirow[t]{2}{*}{14} & \multicolumn{3}{|c|}{ I would not be nervous speaking English with native speakers } \\
\hline & 3.02 & 2.97 & -0.21 \\
\hline \multirow[t]{2}{*}{15} & \multicolumn{3}{|c|}{ I get upset when I don't understand what the teacher is correcting } \\
\hline & 2.61 & 2.64 & 0.11 \\
\hline \multirow[t]{2}{*}{16} & \multicolumn{3}{|c|}{ Even if I am well prepared for English class, I feel anxious about it. } \\
\hline & 3.19 & 3.25 & 0.2 \\
\hline \multirow[t]{2}{*}{17} & \multicolumn{3}{|c|}{ I often feel like not going to my English class } \\
\hline & 3.61 & 4.19 & 2.63 \\
\hline \multirow[t]{2}{*}{18} & \multicolumn{3}{|c|}{ I feel confident when I speak in my English class } \\
\hline & 3.25 & 3.08 & -0.79 \\
\hline \multirow[t]{2}{*}{19} & \multicolumn{3}{|c|}{ I am afraid that my English teacher is ready to correct every mistake I make } \\
\hline & 3.31 & 3.28 & -0.12 \\
\hline \multirow[t]{2}{*}{20} & \multicolumn{3}{|c|}{ I can feel my heart pounding when I am going to be called on in my English class } \\
\hline & 2.53 & 2.89 & 1.33 \\
\hline \multirow[t]{2}{*}{21} & \multicolumn{3}{|c|}{ The more I study for an English test, the more confused I get } \\
\hline & 3.61 & 3.53 & -0.35 \\
\hline \multirow[t]{2}{*}{22} & \multicolumn{3}{|c|}{ I don't feel pressure to prepare very well for my English class } \\
\hline & 2.58 & 3.08 & 2.3 \\
\hline \multirow[t]{2}{*}{23} & \multicolumn{3}{|c|}{ I always feel that the other students speak the English language better than I do } \\
\hline & 2.72 & 2.5 & -0.87 \\
\hline \multirow[t]{2}{*}{24} & \multicolumn{3}{|c|}{ I feel very self-conscious of speaking English in front of other students } \\
\hline & 2.75 & 2.81 & 0.22 \\
\hline \multirow[t]{2}{*}{25} & \multicolumn{3}{|c|}{ English class moves so quickly I worry about being getting left behind } \\
\hline & 3.42 & 3.61 & 0.79 \\
\hline 26 & & nd nerv & than in my other classes \\
\hline & 3.33 & 3.94 & 2.26 \\
\hline 27 & & nd conf & in my English class \\
\hline & 2.92 & 3.03 & 0.47 \\
\hline 28 & & my way & ery sure and relaxed \\
\hline & 2.81 & 2.89 & 0.39 \\
\hline 29 & & I don' & the English teacher says \\
\hline & 3.25 & 3.28 & 0.13 \\
\hline 30 & & by the $\mathrm{r}$ & to learn to speak English \\
\hline & 3.44 & 3.53 & 0.38 \\
\hline 31 & & other st & when I speak English \\
\hline & 3.36 & 3.5 & 0.52 \\
\hline 32 & & ly feel c & e speakers of English \\
\hline & 2.92 & 3.08 & 0.75 \\
\hline 33 & & glish tea & ch I haven't prepared in advance \\
\hline & 2.69 & 3.33 & 2.68 \\
\hline
\end{tabular}




\section{Results and Discussions}

The comparative analysis of the students' responses to the FLCAS questionnaire at the beginning and end of the Spring Semester, 2020, has revealed a general tendency of anxiety to grow due to the changes in learning context and the character of distance learning (lack of personal contact, Zoom fatigue, deadlines etc.). These changes reflect the growth of students' negative attitude to English classes, decrease of motivation and general avoidance. Some students responded they didn't feel like attending their English classes" $(t=2.63)$, others felt more anxious and nervous in their English class than in other classes $(t=$ 2.26). Simultaneously, flexibility of the schedule, growing autonomy of the students, weakening of the tutor's control created favorable conditions for the students to enjoy foreign language distance learning more, which is evident from the responses to the statements "I don't feel pressure to prepare very well for my English class" $(t=2.3)$, "It wouldn't bother me at all to take more English language classes $(t=-2.49)$.

There have also been observed certain changes in the level of such types of foreign language anxiety as "communication apprehension", "fear of making mistakes", "test anxiety" and "fear of negative evaluation". To make the analysis more representative, all the responses have undergone careful consideration - those with absolute value of the t-statistics, greater than the critical value (1.9), as well as those which reflected slight changes in the level and character of anxiety.

\section{Communication Apprehension}

The analysis has shown a certain growth of the communication anxiety which is reflected in the fear of spontaneous speaking and the fear of speaking in front of the class. The former can be traced in the feeling of nervousness the students experience when they are expected to answer the questions they didn't prepare in advance $(\mathrm{t}=2.68)$; their starting to panic when they have to speak without preparation $(\mathrm{t}=0.72)$, lack of confidence when they are speaking in their English class $(t=0.47)$. The latter is seen from the students' feeling self-conscious of speaking English in front of the class $(\mathrm{t}=0.22)$, their experiencing embarrassment to volunteer answers in the English class $(\mathrm{t}=0.53)$, some physical manifestations, like a "pounding heart' and shaking hands $(\mathrm{t}=1.33)$.

Such a growth of communication apprehension can be accounted for by peculiarities of online communication (lack of opportunity to express active listening or understanding by means of backchannelling; lack of verbal emotional support and prompts from the teacher and fellow-students).

\section{Fear of Negative Evaluation}

There has been noticed a significant growth of fear of negative evaluation in language learning at a distance, comparing to the students' scores in traditional classes. The response to the statement "I keep thinking that the other students are better at English than I am" $(\mathrm{t}=2.29)$ clearly demonstrates this tendency. We suppose that one of the reasons for the learners' fear of negative evaluation in the distance setting may be limited or no feedback from the teacher due to restricted possibilities of online classes. Lack of eye contact, delayed feedback from the peers add to the feeling of insecurity and uncertainty. Anxiety also increases if students are grouped for discussions randomly and they can not be certain that their group mates will respond positively to their contribution to the discussion. On a physical level such students feel their heart pounding when they are going to be called in their English class $(\mathrm{t}=1.33)$. They tend to feel "more tense and nervous" in their English class than in other classes $(t=2.26)$. Consequently, students with a high level of fear of negative evaluation demonstrate avoidance tendency and often feel like not going to their English class at all $(\mathrm{t}=2.63)$. Moreover, the difficulty for the tutor to identify the learners' foreign language anxiety symptoms in the distance environment makes this problem more complicated to solve.

\section{Fear of Making Mistakes}

The students' fear of making mistakes has noticeably reduced compared with the traditional classroom setting as seen from the responses to the statements "I don't worry about making mistakes in my English class' ( $\mathrm{t}=$ -2.29), "I am afraid that my English teacher is ready to correct every mistake I make" $(\mathrm{t}=-0.12)$. This tendency can be explained by the fact that in the new online learning conditions, in particular, when working synchronically in pairs or small groups in Zoom "session halls", but yet isolated from the rest of the peers and the teacher, the students felt safer, more confident and autonomous. The possible reasons for this are reduced control and formal assessment from the teacher and lack of evaluation on the part of the other more competent students, which, altogether, contributed to anxiety reduction and learner-centeredness of this mode of learning.

\section{Test Anxiety}

There has also been discovered a slight decrease of the students' test anxiety level from the response to the statement "The more I study for an English test, the more confused I get" $(t=-0.35)$. We assume that this change has taken place due to the fact that during quarantine period tests, more than ever before, became an ongoing part of the learning process, which allowed the students to considerably develop their test-taking strategies and skills, made their preparation for them more focused and 
systematic.

The aforementioned results of the survey show the growth of learners' anxiety as a consequence of the changing learning context, transition from classroom to distance learning.

\section{Implications for Teaching}

We believe that foreign language anxiety can be effectively prevented or dealt with if the students are aware of its symptoms and causes as well as of their own emotions and feelings, are equipped with effective communication strategies and tools.

Ways of reducing communication apprehension and fear of negative evaluation: teaching students how to

- become attentive listeners and use corresponding linguistic signals indicating active listening

- use compensatory strategies such as avoidance, approximation, substitution, generalization, exemplification, description, asking for repetition or clarification

- use backchannelling signals and fillers

- provide positive feedback and friendly peer support by means of functional exponents, expressing praise, encouragement, sympathy

- use computer tools (raised hand in Zoom, emoticons, chat boxes) which are a part of online communication

Ways of preventing and dealing with the fear of making mistakes:

- giving students more autonomy and free choice of speaker partners, speech situations, linguistic means and communication strategies

- increasing peer-, self-evaluation and informal assessment

- changing attitude to mistakes by regarding them as a natural part of the learning process

- developing students' self-awareness and self-control

- providing students with effective techniques of self-correction

\section{Conclusion}

The present study was conducted to explore the difference in Ukrainian students' foreign language anxiety level in classroom and distance learning environments. With regard to the research questions set at the beginning of the study, we have obtained the following results. The transition from traditional classroom to distance online mode of learning has had a considerable effect, both positive and negative, on all the types of students' foreign language anxiety. There has been observed a significant increase of "communication apprehension" and "fear of negative evaluation" anxiety types and a slight decrease of "test anxiety' and "fear of making mistakes". The factors and reasons for such changes have been analyzed and defined. Among the negative-bearing reasons and factors are the following - the changes in the learning context and the character of distance learning, online communication itself, lack of personal contact, Zoom fatigue, deadlines, lack of opportunity to express active listening or understanding by means of backchannelling, lack of verbal emotional support, prompts and feedback from the tutor and fellow-students. The reasons for positive changes in the students' foreign language anxiety levels are - flexibility of the schedule, growing autonomy of the students, weakening of the teacher's control, lack of evaluation on the part of the other more competent students and the teacher, when working synchronically in pairs or small groups in Zoom "session halls", but yet isolated from the whole class, improved test-taking strategies and skills due to regular test-taking practice during the quarantine period.

Possible ways of reducing foreign language anxiety have been suggested. We believe that foreign language anxiety can be effectively prevented or dealt with if the students are aware of its symptoms and causes as well as of their own emotions and feelings and know how to: become attentive listeners and use corresponding linguistic signals indicating active listening; use compensatory strategies such as avoidance, approximation, substitution, generalization, exemplification, description, asking for repetition or clarification; use backchannelling signals and fillers; use computer tools (raised hand in Zoom, emoticons, chat boxes) which are a part of online communication; experience more peer- and self-evaluation; choose effective techniques of self-correction; change attitude to mistakes by regarding them as a natural part of the learning process.

Since foreign language is a specific discipline which implies student's desire to actively participate in the process of learning, foreign language anxiety should be specifically dealt with by both teachers and students. Both parts should be fully aware of its symptoms and its inhibiting influence on learners and learning. Teachers and students can benefit from this investigation while choosing effective strategies of preventing and reducing foreign language anxiety.

The perspectives of the further study may be dedicated to the exploration of the teachers' anxiety domain in the distance online learning context.

\section{REFERENCES}

[1] M. Gordon, M., S. B. Sarason. The relationship between 'test anxiety' and 'other anxieties', Journal of Personality, Vol. 23, 317-23, 1955.

[2] D. Watson, R. Friend. Measurement of social-evaluative 
anxiety, Journal of Consulting and Clinical Psychology, Vol.33, 448-51, 1969.

[3] E. K. Horwitz, M. B. Horwitz, J. Cope. Foreign language classroom anxiety, The Modern Language Journal, Vol. 70, No.2, 125-132, 1986.

[4] P. D. MacIntyre, R. C. Gardner. Anxiety and second language learning: towards a theoretical classification, Language Learning, Vol. 39, No.2, 252-275, 1989.

[5] P. D. MacIntyre, R. C. Gardner. Methods and results in the study of anxiety and language learning: a review of the literature, Language learning, Vol. 41, No. 1, 85-117, 1991.

[6] E. M. Phillips. The effects of language anxiety on students' oral test performance and attitudes, The Modern Language Journal, Vol. 76, No.1, 14-26, 1992.

[7] D. J. Young. An investigation of students' perspectives on anxiety and speaking, Foreign Language Annals, Vol. 23, No.6, 539-548, 1990.

[8] S. M. Algahtani. The impact of language anxiety on EFL learners' proficiency: case study of university of Jeddah, Vol. 8, No. 12, 844-864, 2019.

[9] H.-T. D. Huang. Modeling the relationship between anxiety and performance in second/foreign language speaking assessment, Learning and Individual Differences, Vol. 63, 44-56, 2018.

[10] Z. Kralova, G. Petrova. Causes and consequences of foreign language anxiety, XLinguae Journal, Vol. 10, No.3, 110-122, 2017.

[11] J. Batiha, N. Mohd, R. Mustaffa. Exploring the factors of classroom anxiety in the context of EFL Arab Students, International Journal of Social Science and Humanities Research, Vol. 2, No.2, 18-31, 2014.

[12] O. Suwantaratip, S. Wichadee. The impacts of cooperative learning on anxiety and proficiency in an EFL class, Journal of College Teaching and Learning, Vol. 7, No. 11, 51-57, 2010 .

[13] A. Fakiah. The influence of teachers' anxiety reducing strategies on learners' foreign language anxiety, Innovation in Language Learning and Teaching, Vol. 9, 163-190, 2015.

[14] S. Hurd. Anxiety and non-anxiety in a distance language learning environment: the distance factor as a modifying influence system, System, Vol. 35, No . 4, 487-508, 2007.

[15] K. Nielson, M. Gonzalez-Lloret. Learning foreign languages at a distance. Characteristics of effective online courses, Online available from: https://www.academia.edu/ 9323865

[16] N. Kock. The psychobiological model: towards a new theory of computer-mediated communication based on Darwinian evolution, Organization Science, Vol. 15, No.3, 327-348, 2004.

[17] C. J. White. Autonomy and strategy use in distance foreign language learning: research findings. System, Vol. 23, No. 2, 207-221, 1995.

[18] M. Hauck, S. Hurd. Exploring the link between language anxiety and learner self-management in face-to-face and virtual language learning contexts. European Journal of Open, Distance and E-Learning (EURODL) II., 2005, Online available from: https://www.eurodl.org/materials/co ntrib/2005/Mirjam_Hauck.htm

[19] W. Wang, J. Zhan. The Relationship between English language learner characteristics and online self-regulation: a structural equation modeling approach, Sustainability, Vol.12, 2020, Online available from:https:/www.researchg ate.net/publication/340567014

[20] V. Russell. Language anxiety and the online learner, Foreign Language Annals, Vol. 53, No. 2, 338-352, 2020.

[21] O. J. Jegede, J. Kirkwood. Students' anxiety in learning through distance education. Distance Education, Vol. 15, No. 2, 279-290, 1994

[22] M. Ajmal, S. Ahmad. Exploration of anxiety factors among students of distance learning: a case study of Allama Iqbal Open University, Bulletin of Education and Research, Vol. 41, No. 2, 67-78, 2019

[23] P. Huang, Y. Hwang. An exploration of EFL learners anxiety and e-learning environments. Journal of Language Teaching and Research, Vol. 4, No.1, 27-35, 2013.

[24] S. Aydin. Technology and foreign language anxiety: implications for practice and future research, Journal of Language and Linguistic Studies, Vol. 14, No.2, 193-211, 2018.

[25] F. A. Majid, W. N. E. H. Sharil, J.E. Luaran, F. A. Nadzri. A study on the on-line language learning anxiety among adult learners, International Journal of e-Education, e-Business, e-Management and e-Learning, Vol. 2, No. 3, 187-192, 2012.

[26] F. Pichette. Second language anxiety and distance language learning, Foreign Language Annals, Vol. 42, No. 1, 77-93, 2009.

[27] A. S. Bollinger. Foreign language anxiety in traditional and distance learning foreign language classes, Doctoral Dissertations and Projects, 2017, Online available from: https://digitalcommons.liberty.edu/doctoral/1429

[28] E. K. Horwitz. Preliminary evidence for the reliability and validity of a foreign language anxiety scale. TESOL Quarterly, Vol. 20, No. 3, 559-564, 1986. 